\title{
Clinical outcomes following advanced respiratory motion management (respiratory gating or dynamic tumor tracking) with stereotactic body radiation therapy for stage I non-small-cell lung
} cancer

This article was published in the following Dove Press journal: Lung Cancer:Targets and Therapy

\author{
Paul Aridgides' \\ Tamara Nsouli' \\ Rishabh Chaudhari' \\ Russell Kincaid' \\ Paula F Rosenbaum² \\ Sean Tanny' \\ Michael Mix' \\ Jeffrey Bogart' \\ 'Department of Radiation Oncology, \\ SUNY Upstate Medical University, \\ Syracuse, NY 13210, USA; \\ ${ }^{2}$ Department of Public Health and \\ Preventive Medicine, SUNY Upstate \\ Medical University, Syracuse, NY \\ 13210 , USA
}

Purpose: To report the outcomes of stereotactic body radiation therapy (SBRT) for stage I non-small-cell lung cancer (NSCLC) according to respiratory motion management method.

Methods: Patients with stage I NSCLC who received SBRT from 2007 to 2015 were reviewed. Computed tomography $(\mathrm{CT})$ simulation with four-dimensional $\mathrm{CT}$ was performed for respiratory motion assessment. Tumor motion $>1 \mathrm{~cm}$ in the craniocaudal direction was selectively treated with advanced respiratory management: either respiratory gating to a pre-specified portion of the respiratory cycle or dynamic tracking of an implanted fiducial marker. Comparisons were made with internal target volume approach, which treated all phases of respiratory motion.

Results: Of 297 patients treated with SBRT at our institution, 51 underwent advanced respiratory management (48 with respiratory gating and three with tumor tracking) and 246 underwent all-phase treatment. Groups were similarly balanced with regard to mean age $(P=0.242)$, tumor size $(P=0.315)$, and histology $(P=0.715)$. Tumor location in the lower lung lobes, as compared to middle or upper lobes, was more common in those treated with advanced respiratory management (78.4\%) compared to all-phase treatment $(25.6 \%, P<.0001)$. There were 17 local recurrences in the treated lesions. Kaplan-Meier analyses showed that there were no differences with regard to mean time to local failure ( 91.5 vs 98.8 months, $P=0.56)$, mean time to any failure $(73.2$ vs 78.7 months, $P=0.73$ ), or median overall survival ( 43.3 vs 45.5 months, $P=0.56$ ) between patients who underwent advanced respiratory motion management and all-phase treatment.

Conclusion: SBRT with advanced respiratory management (the majority with respiratory gating) showed similar efficacy to all-phase treatment approach for stage I NSCLC.

Keywords: SBRT, respiratory gating, lung cancer, radiation therapy, medically inoperable, stage I

\section{Introduction}

Stereotactic body radiation therapy (SBRT) has been shown to be highly effective for the treatment of stage I non-small-cell lung cancer (NSCLC), ${ }^{1}$ with long-term followup showing 5-year local tumor control of 93\%. ${ }^{2}$ SBRT was initially developed for treatment of patients unfit to undergo surgery (medically inoperable). ${ }^{3-5}$ Prospective studies comparing SBRT to surgery for medically operable patients, while limited by low numbers of patients due to difficult accrual, suggest similar outcomes between SBRT and lobectomy. ${ }^{6}$ In addition to treatment of medically operable patients, ${ }^{7,8}$ active
Correspondence: Paul Aridgides Department of Radiation Oncology, SUNY Upstate Medical University, 750 East Adams Street, Syracuse, NY 13210 , USA

Email aridgidp@upstate.edu 
research into optimal fraction number and $\operatorname{dose}^{9-12}$ as well as tolerability for centrally located tumors ${ }^{12-14}$ is ongoing.

To ensure accurate and safe delivery of highly conformal, high-dose-per-fraction treatment (12-20 Gy), SBRT requires a greater focus on patient immobilization as well as real-time tumor imaging for target confirmation. ${ }^{15}$ One commonly used technique to assess tumor motion during the respiratory cycle is four-dimensional computed tomography (4DCT). The management of respiratory motion can be particularly critical, as tumor movement of up to 5 $\mathrm{cm}$ has been documented. ${ }^{16,17}$ This may be accomplished through target designation of an internal target volume (ITV) encompassing all phases of respiratory motion. Alternatively, advanced techniques that monitor motion and modify treatment in real time offer the dosimetric advantage of smaller target volumes and lower dose to organs at risk. ${ }^{18}$ These include respiratory gating, which delivers treatment only to a pre-specified portion of the respiratory cycle, and tumor tracking, where tumor motion is followed by dynamic movement of the treatment field. To ensure that incorporation of these advanced techniques did not compromise local control, we retrospectively analyzed outcomes of patients with stage I NSCLC treated with SBRT in our institution according to the method of respiratory management.

\section{Materials and methods}

We retrospectively reviewed outcomes of patients treated with SBRT for stage I NSCLC between 2007 and 2015 at our institution. The SUNY Upstate Medical University Institutional Review Board (IRB) for the Protection of Human Subjects approved this study with determination that patient consent was not required by the IRB, since patient data confidentiality was maintained and all records were retrospective (approval ID: 910050-1). The population included 297 patients with 351 treated lesions. In cases of metachronous lesions that developed after a tumor that previously received SBRT, statistical comparisons were limited to the initially treated lesion. Patients received SBRT due to being poor candidates for surgery, medically inoperable, or declining surgery. Patients were immobilized using wholebody fixation devices. Abdominal compression was applied to restrict respiratory motion for patients who could tolerate it, with the exception of patients identified as candidates for dynamic tumor tracking. To assess tumor motion due to respiration, a 4DCT scan was performed at simulation with both a radiation oncologist and a physicist present. The four-dimensional scan was acquired on a four-slice
CT scanner (Lightspeed; GE Medical Systems, Chicago, IL, USA) with an external respiratory monitoring system (Real-time Position Management [RPM] System, Varian Medical Systems, Palo Alto, CA, USA). The RPM system uses an infrared tracking camera that follows an external marker placed on the patient's abdomen to determine phases of the respiratory cycle. The respiratory cycle is divided into $10 \%$ segments, with $0 \%$ being end-inhalation and $50 \%$ being end-exhalation. The $4 \mathrm{DCT}$ is obtained from a cine scan, correlated with the RPM data, by sorting images into ten phase bins (GE Advantage 4D). The 4DCT phase bin images allow visualization throughout the respiratory cycle. Respiratory motion was assessed, and patients with tumor motion $<1 \mathrm{~cm}$ were assigned to receive treatment using an all-phase ITV approach. Patients with tumor motion $>1 \mathrm{~cm}$ were assigned to receive treatment using advanced motion management techniques.

Respiration gating limits delivery of the treatment beam to within a specified respiratory gate. The gate interval was chosen after joint review by the radiation oncologist and radiation physicist. The most commonly used gating phases were $20 \%-$ $70 \%$ (28\% of gated patients) and $20 \%-60 \%$ (23\% of gated patients). Dynamic tumor tracking uses orthogonal real-time radiographic imaging to track radio-opaque implanted fiducial markers. The three-dimensional positions of the fiducial markers are used to create a predictive respiratory model, which controls a gimbal mounted accelerator head on the Vero linear accelerator. The treatment beam is continuously provided that the fiducial marker does not exceed a user-defined tolerance of the predictive model used to control the accelerator. Our institution used a tolerance of $3 \mathrm{~mm}$, with an automatic beam hold if the tumor exceeded the $3 \mathrm{~mm}$ threshold for $>3$ seconds.

Treatment planning included a gross tumor volume (GTV) with a planning tumor volume (PTV) expansion that was variable $(0.5-1 \mathrm{~cm})$ and customized for each patient, consistent with established guidelines. ${ }^{19,20}$ The SBRT prescription required $95 \%$ of PTV receives $100 \%$ of prescribed dose, with the goal of minimizing the maximum point dose to $<115 \%$. For three-dimensional conformal radiation therapy (3DCRT), this entailed prescribing to the required isodose line (IDL) of the plan (typical $75 \%-85 \%$ IDL, range 60\%-90\%) to ensure this is achieved. For intensity-modulated radiation therapy (IMRT)-based plans, this requires renormalization of the plan until this benchmark is met. An institutional study comparing GTV dose/volume coverage, as it relates to SBRT outcomes and dose prescribed to the PTV, is ongoing.

Patients were treated on one of the four treatment machines: Varian 21EX, Varian TrueBeam, Accuray Tomo- 
therapy, and Brainlab Vero. Gated patients (Table 1) were treated on either Varian 21EX or Varian TrueBeam. Dynamic tracking patients (three patients) were treated on Vero. All patients treated using advanced motion management techniques were subjected to $3 \mathrm{D}$ conformal radiation therapy (3DCRT), as respiratory-gated IMRT had not yet been adopted by our institution during this time period. Patients treated using an all-phase ITV were treated on a Varian machine, Tomotherapy, or Vero. All treatments, regardless of motion management technique, were performed using image-guided radiation therapy (IGRT with volumetric setup imaging prior to treatment, eg, $\mathrm{kV}$ cone beam $\mathrm{CT}$ or megavoltage $\mathrm{CT}$ ). Cine mode portal verification imaging was used during treatment of non-IMRT fields.

Data were collected on patient characteristics, tumor characteristics, treatment parameters, toxicity during follow-up, survival, and recurrence. A number of patients were noted to have metachronous lesions; consequently, information about each lesion was collected individually. Patients were assessed weekly during treatment, and subsequently seen in follow-up with CT imaging 1 month after finishing therapy and then every 4-6 months for 5 years and then annually. Fludeoxyglucose positron emission tomography imaging

Table I SBRT characteristics of patients who received advanced respiratory management (respiratory gating or tracking) and those who were treated during all phases of the respiration

\begin{tabular}{|c|c|c|c|c|c|}
\hline \multirow[t]{2}{*}{ Characteristic } & \multicolumn{2}{|c|}{$\begin{array}{l}\text { All phases } \\
(\mathrm{N}=246)\end{array}$} & \multicolumn{2}{|c|}{$\begin{array}{l}\text { Advanced } \\
\text { respiratory } \\
\text { management } \\
(\mathrm{N}=5 \mathrm{I})\end{array}$} & \multirow[t]{2}{*}{$P$-value } \\
\hline & $n$ & $\%$ & $\mathbf{n}$ & $\%$ & \\
\hline \multicolumn{6}{|l|}{ Fractions } \\
\hline$I$ & 3 & 1.20 & 0 & 0.00 & 0.45 \\
\hline 3 & 79 & 32.1 & 17 & 33.0 & \\
\hline 4 & 127 & 51.6 & 30 & 58.8 & \\
\hline 5 & 37 & 15.0 & 4 & 7.80 & \\
\hline \multicolumn{6}{|l|}{ Machine } \\
\hline 2IEX & 93 & 37.8 & 39 & 76.5 & $<0.0001$ \\
\hline TrueBeam & 7 & 2.80 & 9 & 17.6 & \\
\hline Vero & 22 & 8.90 & 3 & 5.90 & \\
\hline Tomotherapy & 124 & 50.4 & 0 & 0.00 & \\
\hline \multicolumn{6}{|l|}{ Modality } \\
\hline 3DCRT & 113 & 45.9 & 42 & 82.4 & $<0.0001$ \\
\hline IMRT & 133 & 54.1 & 9 & 17.6 & \\
\hline \multicolumn{6}{|l|}{ Beam energy } \\
\hline $6 \mathrm{MV}$ & 233 & 94.7 & 40 & 78.4 & 0.0001 \\
\hline $\begin{array}{l}18 \mathrm{MV} \text { or } \\
\text { mixed }\end{array}$ & 13 & 5.30 & 11 & 21.6 & \\
\hline
\end{tabular}

Abbreviations: SBRT, stereotactic body radiation therapy; 3DCRT, threedimensional conformal radiation therapy; IMRT, intensity-modulated radiation therapy. was generally performed following SBRT only if there was suspicion of recurrence on CT imaging.

Outcomes assessed were overall survival, recurrence rates, and toxicity from radiation treatment for the entire cohort and those who received/not received respiratory management. All analyses were conducted using SPSS statistical software and included frequencies of categorical variables (eg, sex, lobe of lung, pathology, and radiation pneumonitis) as well as means and SDs for continuous variables such as age, body mass index, or maximum tumor diameter. Other statistical procedures included $t$-tests to compare means of continuous variables across respiratory management groups (with and without gating). Chi-square tests were used to assess possible associations across pairs of categorical variables (eg, respiratory management vs pathology, machine type, sex, lobe of lung, treatment modality, and treatment year). Kaplan-Meier analyses were also undertaken to examine overall survival and time to local failure by respiratory management and to calculate mean and/or median survival times/time to event; $P$-values were assessed using the log-rank test in these comparisons. Mean time to local failure was calculated as only $7 \%$ of the participants had experienced a failure at the time of the analysis; the median could not be calculated as $<50 \%$ had not experienced the event of interest. Finally, Cox proportional hazards modeling was used to assess the effects of respiratory management on overall survival with control for age, sex, number of lesions (one, more than one), and tumor size (in $\mathrm{cm}$ ). Variables also assessed in some of the Cox proportional hazards models were machine type (Tomotherapy, TrueBeam, 21EX, and Vero) and treatment modality (IMRT, 3DCRT). Statistically significant differences were based on a $P$-value of $\leq 0.05$; HRs and $95 \%$ CIs were reported for parameters in the Cox models.

\section{Results}

\section{Patient characteristics}

A total of 297 patients with 351 stage I NSCLC lesions were included in this study. The mean and median follow-up periods were 27.9 and 20.8 months, respectively (range 0.5-107 months). An overview of the characteristics of those who received treatment with advanced respiratory management and during all phases is outlined in Table 1.

\section{Tumor characteristics}

A summary of the tumor characteristics and treatment parameters compared between the two groups is shown in Table 2 . A majority of the lesions were T1A (68\%), located in the upper lobes $(60.9 \%)$, and had adenocarcinoma pathology (49.5\%). 
Patients who received advanced respiratory management had significantly more lesions treated in the lower lobes $(78.4 \%)$ as compared with the all-phase subgroup $(25.6 \% ; P<0.001)$. No significant differences in pathology or $\mathrm{T}$ stage were seen between respiratory management techniques, and the mean tumor diameter was similar in both groups (Table 2).

\section{Treatment parameters}

The most common fractionation regimens used were $48 \mathrm{~Gy}$ in four fractions (52.9\%) and 54/60 Gy in three fractions (32.2\%). Overall, patients were more frequently treated on the Varian 21EX (44.4\%) and Tomotherapy (41.8\%) machines. However, those who received advanced respiratory gating were treated mostly on the Varian 21EX (76.5\%) machine. Median duty cycle was $50 \%$ (range $40 \%-70 \%$ ), with the most commonly used gating phases being $20 \%-70 \%$ (28.3\% of lesions) and $20 \%-60 \%$ (22.6\% of lesions) of the respiratory cycle.

Table 2 Patient and tumor characteristics compared between patients who received advanced respiratory management and those who received treatment during all phases

\begin{tabular}{|c|c|c|c|c|c|}
\hline \multirow[t]{2}{*}{ Characteristic } & \multicolumn{2}{|c|}{$\begin{array}{l}\text { All phases } \\
(\mathrm{N}=246)\end{array}$} & \multicolumn{2}{|c|}{$\begin{array}{l}\text { Advanced } \\
\text { respiratory } \\
\text { management } \\
(\mathrm{N}=5 \mathrm{I})\end{array}$} & \multirow[t]{2}{*}{$P$-value } \\
\hline & $\mathbf{n}$ & $\%$ & $\mathbf{n}$ & $\%$ & \\
\hline $\begin{array}{l}\text { Age, years, } \\
\text { mean (SD) }\end{array}$ & \multicolumn{2}{|c|}{$70.2(9.6)$} & \multicolumn{2}{|c|}{$71.9(10.4)$} & 0.24 \\
\hline \multicolumn{6}{|l|}{ Gender } \\
\hline Female & 122 & 49.6 & 21 & 41.2 & 0.27 \\
\hline Male & 124 & 50.4 & 30 & 58.8 & \\
\hline \multicolumn{6}{|l|}{ Indication } \\
\hline $\begin{array}{l}\text { Medically } \\
\text { inoperable }\end{array}$ & 169 & 68.7 & 36 & 70.6 & 0.79 \\
\hline Declined surgery & 77 & 31.3 & 15 & 29.4 & \\
\hline $\begin{array}{l}\text { Mean maximum } \\
\text { diameter }(\mathrm{cm})\end{array}$ & 1.88 & 100 & 1.71 & 100 & 0.32 \\
\hline \multicolumn{6}{|l|}{ T-stage } \\
\hline TIA & 167 & 67.9 & 35 & 68.6 & 0.59 \\
\hline TIB & 54 & 22.0 & 13 & 25.5 & \\
\hline T2A & 25 & 10.2 & 3 & 5.90 & \\
\hline \multicolumn{6}{|l|}{ Location } \\
\hline RUL/RML/LUL & 183 & 74.4 & 11 & 21.6 & $<0.0001$ \\
\hline LLL/RLL & 63 & 25.6 & 40 & 78.4 & \\
\hline \multicolumn{6}{|l|}{ Pathology } \\
\hline Adenocarcinoma & 117 & 50.6 & 30 & 58.8 & 0.72 \\
\hline Squamous & 88 & 38.1 & 14 & 28.0 & \\
\hline Other, NSCLC & 26 & 11.3 & 6 & 11.7 & \\
\hline \multicolumn{6}{|l|}{ Biopsy } \\
\hline Yes & 231 & 93.9 & 50 & 98.0 & 0.23 \\
\hline No & 15 & 6.10 & 1 & 2.00 & \\
\hline
\end{tabular}

Note: Patients with multiple lesions are listed according to their first-treated lesion, which was used for all statistical comparisons.

Abbreviations: RUL, right upper lobe; RML, right middle lobe; LUL, left upper lobe; LLL, left lower lobe; RLL, right lower lobe; NSCLC, non-small-cell lung cancer.

\section{Recurrence}

The time to local recurrence according to the method of respiratory management is shown in Figure 1. There were a total of 17 local recurrences in the treated lesions, 10 of which had pathologic confirmation. The other seven were confirmed radiologically. Local recurrence was cross tabulated with individual treatment parameters and found to not have any significant difference with respect to advanced respiratory management, treatment modality, treatment machine, beam energy, maximum diameter, fractionation regimen, pathology, or T-stage. Kaplan-Meier analysis showed that there was no difference in mean time to either local failure, last follow-up, or death between patients treated with advanced respiratory management (mean 91.5 months) or all-phase treatment (98.8 months, $P=0.56$ ). Nodal and distal recurrences were similarly unaffected by these parameters. Time to any failure was not significantly different between the advanced respiratory management and all-phase groups (73.2 vs 78.7 months; log-rank test, $P=0.73$ ). There were no local failures in the dynamic tracking subset of the advanced respiratory management cohort.

\section{Overall survival}

Overall survival according to the method of respiratory management is shown in Figure 2. The median overall survival time was 43.4 months for all patients and did not differ significantly between those who received advanced respiratory management and those treated during all phases (43.4 and 45.5 months; logrank test, $P$-value $=0.47$ ). In Cox proportional hazards modeling (Table 3 ), the patient's age, number of lesions treated, and size of the tumor were significantly associated with survival. For every additional year of age, there was a 3\% increased chance of death $(P=0.001)$. Patients who had more than one stage I NSCLC lesion treated with SBRT were found to have a $45 \%$ decreased rate of death $(P=0.017)$. This was attributed to selection bias as these patients survived with reasonable performance status to allow treatment of a subsequent lesion. For every $1.0 \mathrm{~cm}$ increase in tumor diameter, there was an associated $17 \%$ increase in rate of death $(P=0.048)$. In the same model, respiratory gating was not significantly associated with overall survival, with a HR of $0.72 \%$ and a $95 \%$ CI of 0.44-1.19 $(P=0.20)$. Gender and treatment modality, which were the remaining variables in the Cox model, also did not significantly impact the overall survival.

\section{Toxicity}

SBRT was well tolerated without occurrence of any grade $3+$ toxicities during or immediately following treatment. During subsequent follow-up, a total of four grade $\geq 3$ 


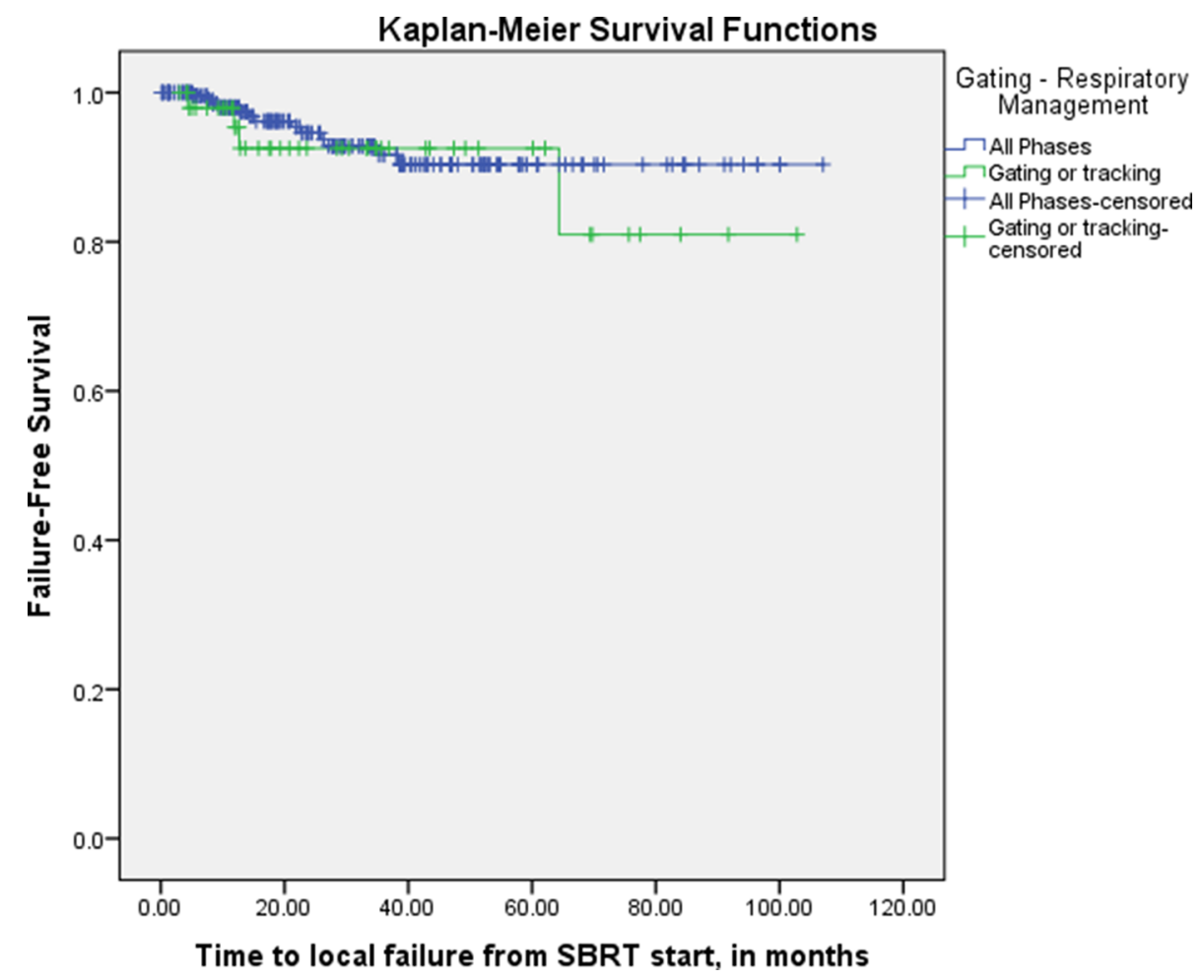

Figure I Time to local failure according to the method of respiratory management.

Note: Time to any failure was not significantly different between the advanced respiratory management and all-phase groups (73.2 vs 78.7 months; log-rank test, $P=0.73$ ). Abbreviation: $\mathrm{RT}$, radiation therapy.

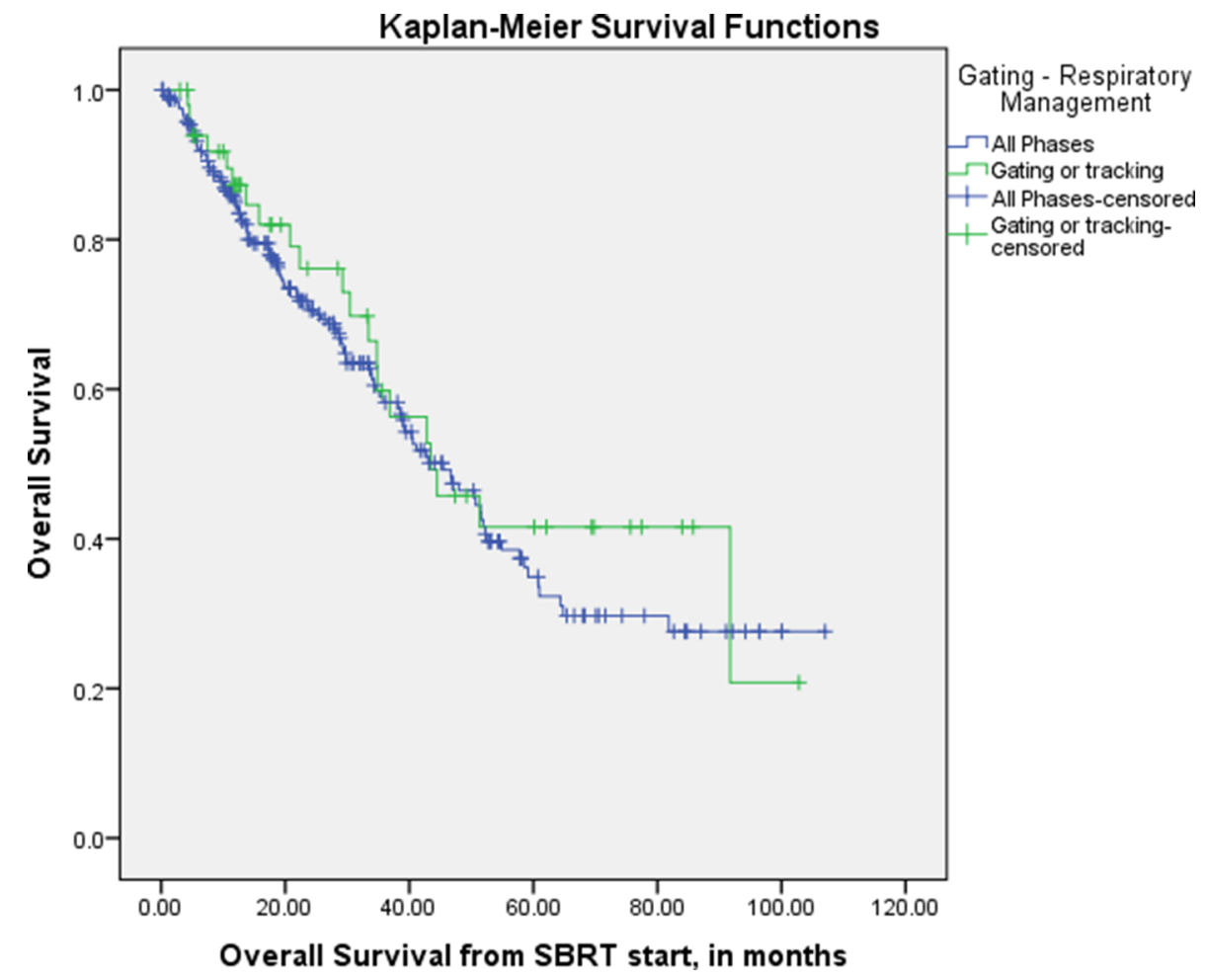

Figure 2 Overall survival according to the method of respiratory management.

Note: Median overall survival was not significantly different between those who received advanced respiratory management and all-phase group (43.4 and 45.5 months; log-rank test, $P=0.47$ ). 
Table 3 Cox Proportional Hazards model with adjusted hazard ratios (AHR), 95 percent confidence intervals $(\mathrm{Cl})$ \& P-values; Outcome was death, $\mathrm{n}=294$ participants

\begin{tabular}{|c|c|c|c|}
\hline $\begin{array}{l}\text { Variables in } \\
\text { Model }\end{array}$ & AHR & $(95 \% \mathrm{CI})$ & P-value \\
\hline *Age in years & 1.03 & $(1.01-1.05)$ & 0.001 \\
\hline Gender: Male & 1.0 & Reference & 0.10 \\
\hline Female & 0.74 & $(0.52-1.06)$ & \\
\hline Respiratory & & & \\
\hline management: No & 1.0 & Reference & 0.20 \\
\hline Yes & 0.72 & $(0.44-1.19)$ & \\
\hline Treatment & & & \\
\hline modality: IMRT & 1.0 & Reference & 0.83 \\
\hline $3 \mathrm{D}$ & 1.04 & $(0.7 I-I .54)$ & \\
\hline $\begin{array}{l}\text { Number } \\
\text { of lesions: Has }\end{array}$ & & & \\
\hline only one & 1.0 & Reference & 0.017 \\
\hline $\begin{array}{l}\text { Has more } \\
\text { than one }\end{array}$ & 0.55 & $(0.33-0.90)$ & \\
\hline $\begin{array}{l}\text { Maximum } \\
\text { diameter in } \mathrm{cm}\end{array}$ & 1.17 & $(1.00-1.37)$ & 0.048 \\
\hline
\end{tabular}

Note: *Coded as 89 if age $\geq 89$ years.

events occurred within the entire group, with no grade 4 or 5 toxicities from treatment observed. These included: grade 3 radiation pneumonitis (one patient, all phases), grade 3 dyspnea (one patient, all phases), grade 3 rib fracture (one patient, advanced respiratory management), and additional grade 3 dyspnea (one patient, advanced respiratory management).

\section{Discussion}

SBRT has been adopted into routine clinical practice over the past 15 years due to multiple institutional and collaborative trials demonstrating excellent local tumor control in high-risk patients with early-stage NSCLC., ${ }^{3,14,21-26}$ The American Society for Radiation Oncology recently issued a new clinical guideline for the use of SBRT, although detailed recommendations regarding motion management were not included. ${ }^{27}$ While motion management is an integral part of SBRT planning, there has been little published evidence regarding the therapeutic ratio when respiratory gating and/or tracking are employed. A retrospective series reporting results of robotic radiosurgery included 42 primary lung tumors, where motion management was achieved through real-time detection of implanted fiducial markers and/or tumors found a 2-year local control of $100 \% .{ }^{28}$ This is a comparable motion management strategy to dynamic tumor tracking used on the
Vero system in the present study. The obvious concerns when treating a moving target only during part of the respiratory cycle is the potential to undertreat the tumor (tumor miss) and/or overtreat the functioning lung tissue if the beam-on time is not accurately and reproducibly correlated with actual tumor position. The current experience suggests the careful use of advanced respiratory management techniques in SBRT for stage I NSCLC does not compromise efficacy or increase toxicity.

Respiratory management requires consideration of treatment planning variables (margin size), image guidance (pretreatment and intra-fraction), immobilization method (compression and body fixation), and mode of delivery (3DCRT, IMRT, or volumetric arc therapy). Our institutional lung SBRT program is standardized with regard to immobilization abdominal compression. Image-guidance protocols continue to evolve, but for the duration of this study, all patients treated with 3DCRT had both pre-fraction cone beam (CB) CT and real-time portal (megavoltage) cine mode target visualization. IMRT plans had pre- and intra-fraction CBCT. In all cases, IGRT (including cine mode during delivery) was verified by a radiation oncologist. Contouring of the GTV was performed on either maximal intensity projection CT (treating all phases or tracking) or CT for selected phases of the respiratory cycle (gating). PTV margins were customized to each patient, but benchmark margins from RTOG 0236 (1 cm superior-inferior and $0.5 \mathrm{~cm}$ radially) were the accepted standard.

The incorporation of respiratory gating in SBRT confers a dosimetric advantage, ${ }^{29-31}$ which, to our knowledge, has yet to be reported with regard to clinical efficacy. We found no difference in local failure or survival comparing respiratory gating (and three patients with tumor tracking) to treating all phases of respiratory motion. While being retrospective in nature, the number of patients (297) and length of follow-up are strengths of this analysis. Other limitations include relatively few numbers of local recurrences in both the groups and inclusion of few patients with tumor tracking. We chose to include in our report dynamic tracking patients treated on the Vero machine as this is an emerging and relatively novel technology, ${ }^{32}$ with similarities to respiratory gating as there is real-time monitoring and modification of treatment delivery according to respiratory motion.

There are several caveats to routine implementation of respiratory gating in SBRT. Patients with tumor motion $<1$ $\mathrm{cm}$ in the craniocaudal direction, or with non-reproducible breathing patterns, received treatment to all phases of respi- 
ratory motion. The vast majority (82\%) of cases of SBRT with respiratory gating (or tumor tracking) had 3DCRT, since the technology for gated volumetric arc radiation therapy/ IMRT at our center has only recently become available. In comparison, 3DCRT was only utilized in $46 \%$ of cases of all-phase SBRT. However, no differences with regard to local failure or survival according to the mode of delivery (3DCRT or IMRT) were observed, which is the subject of our subsequent report. ${ }^{33}$

\section{Conclusion}

Combined with detailed assessment of respiratory motion at the time of CT simulation, incorporation of respiratory gating in SBRT for the treatment of stage I NSCLC did not impact treatment efficacy. We are therefore continuing the selective use of advanced respiratory management strategies with SBRT for the treatment of appropriately selected patients with stage I NSCLC.

\section{Disclosure}

The authors report no conflicts of interest in this work.

\section{References}

1. Aridgides $P$, Bogart J. Stereotactic body radiation therapy for stage $i$ non-small cell lung cancer. Thorac Surg Clin. 2016;26(3):261-269.

2. Timmerman RD, Hu C, Michalski J, et al. Long-term Results of RTOG 0236: A phase II trial of stereotactic body radiation therapy (SBRT) in the treatment of patients with medically inoperable stage I non-small cell lung cancer. Int J Radiat Oncol Biol Phys. 2014;90(1):S30.

3. Timmerman R, Papiez L, Mcgarry R, et al. Extracranial stereotactic radioablation: results of a phase I study in medically inoperable stage I non-small cell lung cancer. Chest. 2003;124(5):1946-1955.

4. Timmerman R, Paulus R, Galvin J, et al. Stereotactic body radiation therapy for inoperable early stage lung cancer. JAMA 2010;303(11):1070-1076.

5. Baumann P, Nyman J, Hoyer M, et al. Outcome in a prospective phase II trial of medically inoperable stage I non-small-cell lung cancer patients treated with stereotactic body radiotherapy. $J$ Clin Oncol. 2009;27(20):3290-3296.

6. Chang JY, Senan S, Paul MA, et al. Stereotactic ablative radiotherapy versus lobectomy for operable stage I non-small-cell lung cancer: a pooled analysis of two randomised trials. Lancet Oncol. 2015;16(6):630-637.

7. Onishi H, Shirato H, Nagata Y, et al. Stereotactic body radiotherapy (SBRT) for operable stage I non-small-cell lung cancer: can SBRT be comparable to surgery? Int J Radiat Oncol Biol Phys. 2011;81(5):1352-1358.

8. Robert D. Timmerman D, Pass HI, et al. RTOG 0618: Stereotactic body radiation therapy (SBRT) to treat operable early-stage lung cancer patients. J Clin Oncol. 2013;2013(31 suppl):abstr 7523.

9. Onishi H, Shirato H, Nagata Y, et al. Hypofractionated stereotactic radiotherapy (HypoFXSRT) for stage I non-small cell lung cancer: updated results of 257 patients in a Japanese multi-institutional study. J Thorac Oncol. 2007;2(7 Suppl 3):S94-S100.

10. Lagerwaard FJ, Haasbeek CJ, Smit EF, Slotman BJ, Senan S. Outcomes of risk-adapted fractionated stereotactic radiotherapy for stage I non-small-cell lung cancer. Int J Radiat Oncol Biol Phys. 2008;70(3):685-692.
11. Stephans KL, Djemil T, Reddy CA, et al. A comparison of two stereotactic body radiation fractionation schedules for medically inoperable stage I non-small cell lung cancer: the Cleveland Clinic experience. $J$ Thorac Oncol. 2009;4(8):976-982.

12. Videtic GM, Hu C, Singh AK, et al. A Randomized Phase 2 Study Comparing 2 Stereotactic Body Radiation Therapy Schedules for Medically Inoperable Patients With Stage I Peripheral Non-Small Cell Lung Cancer: NRG Oncology RTOG 0915 (NCCTG N0927). Int J Radiat Oncol Biol Phys. 2015;93(4):757-764.

13. Corradetti MN, Haas AR, Rengan R. Central-airway necrosis after stereotactic body-radiation therapy. N Engl J Med. 2012;366(24):2327-2329.

14. Timmerman R, Mcgarry R, Yiannoutsos C, et al. Excessive toxicity when treating central tumors in a phase II study of stereotactic body radiation therapy for medically inoperable early-stage lung cancer. $J$ Clin Oncol. 2006;24(30):4833-4839.

15. Guckenberger M, Andratschke N, Alheit H, et al. Definition of stereotactic body radiotherapy: principles and practice for the treatment of stage I non-small cell lung cancer. Strahlenther Onkol. 2014;190:26-33.

16. Liu HH, Balter P, Tutt T, et al. Assessing respiration-induced tumor motion and internal target volume using four-dimensional computed tomography for radiotherapy of lung cancer. Int J Radiat Oncol Biol Phys. 2007;68(2):531-540.

17. Brandner ED, Chetty IJ, Giaddui TG, Xiao Y, Huq MS. Motion management strategies and technical issues associated with stereotactic body radiotherapy of thoracic and upper abdominal tumors: A review from NRG oncology. Med Phys. 2017;44(6):2595-2612.

18. Giraud P, Garcia R. Respiratory gating for radiotherapy: main technical aspects and clinical benefits. Bull Cancer. 2010;97(7):847-856.

19. Seuntiens JLE, Cora S. ICRU Report 91. 2014.

20. Moustakis C, Blanck O, Ebrahimi Tazehmahalleh F, et al. Planning benchmark study for SBRT of early stage NSCLC: Results of the DEGRO Working Group Stereotactic Radiotherapy. Strahlenther Onkol. 2017;193(10):780-790.

21. Videtic GM, Reddy CA, Sorenson L. A prospective study of quality of life including fatigue and pulmonary function after stereotactic body radiotherapy for medically inoperable early-stage lung cancer. Support Care Cancer. 2013;21(1):211-218.

22. Bral S, Gevaert T, Linthout N, et al. Prospective, risk-adapted strategy of stereotactic body radiotherapy for early-stage non-small-cell lung cancer: results of a Phase II trial. Int J Radiat Oncol Biol Phys. 2011;80(5):1343-1349.

23. van der Voort van Zyp NC, Prévost JB, van der Holt B, et al. Quality of life after stereotactic radiotherapy for stage I non-small-cell lung cancer. Int J Radiat Oncol Biol Phys. 2010;77(1):31-37.

24. Boily G, Filion E, Rakovich G, et al. Stereotactic Ablative Radiation Therapy for the Treatment of Early-stage Non-Small-Cell Lung Cancer: CEPO Review and Recommendations. J Thorac Oncol. 2015; 10:872-882.

25. Senthi S, Lagerwaard FJ, Haasbeek CJ, Slotman BJ, Senan S. Patterns of disease recurrence after stereotactic ablative radiotherapy for early stage non-small-cell lung cancer: a retrospective analysis. Lancet Oncol. 2012;13(8):802-809.

26. Videtic GM, Stephans K, Reddy C, et al. Intensity-modulated radiotherapy-based stereotactic body radiotherapy for medically inoperable early-stage lung cancer: excellent local control. Int J Radiat Oncol Biol Phys. 2010;77(2):344-349.

27. Videtic GMM, Donington J, Giuliani M, et al. Stereotactic body radiation therapy for early-stage non-small cell lung cancer: Executive Summary of an ASTRO Evidence-Based Guideline. Pract Radiat Oncol. 2017;7(5):295-301.

28. Stera S, Balermpas P, Chan MKH, et al. Breathing-motion-compensated robotic guided stereotactic body radiation therapy: Patterns of failure analysis. Strahlenther Onkol. 2018;194(2):143-155.

29. Jang SS, Huh GJ, Park SY, Yang PS, Cho EY. The impact of respiratory gating on lung dosimetry in stereotactic body radiotherapy for lung cancer. Phys Med. 2014;30(6):682-689. 
30. Xhaferllari I, Chen JZ, Macfarlane M, Yu E, Gaede S. Dosimetric planning study of respiratory-gated volumetric modulated arc therapy for early-stage lung cancer with stereotactic body radiation therapy. Pract Radiat Oncol. 2015;5(3):156-161.

31. Underberg RW, Lagerwaard FJ, Slotman BJ, Cuijpers JP, Senan S. Benefit of respiration-gated stereotactic radiotherapy for stage I lung cancer: an analysis of 4DCT datasets. Int J Radiat Oncol Biol Phys. 2005;62(2):554-560.
32. Kunos CA, Fabien JM, Shanahan JP, et al. Dynamic Lung Tumor Tracking for Stereotactic Ablative Body Radiation Therapy. J Vis Exp. 2015 (100):e52875.

33. Nsouli T, Frandina J, Tanny S, et al. Local tumor control after stereotactic body radiation therapy for early lung cancer is not impacted by the use of intensity modulated radiation therapy or respiratory gating. Int J Radiat Oncol Biol Phys. 2017;99(2):E487.

\section{Publish your work in this journal}

Lung Cancer: Targets and Therapy is an international, peer-reviewed, open access journal focusing on lung cancer research, identification of therapeutic targets and the optimal use of preventative and integrated treatment interventions to achieve improved outcomes, enhanced survival and quality of life for the cancer patient. Specific topics covered in the journal include: Epidemiology, detection and screening; Cellular research and biomarkers; Identification of biotargets and agents with novel

Submit your manuscript here: https://www.dovepress.com/lung-cancer-targets--therapy-journal mechanisms of action; Optimal clinical use of existing anticancer agents, including combination therapies; Radiation and surgery; Palliative care; Patient adherence, quality of life, satisfaction; Health economic evaluations. The manuscript management system is completely online and includes a very quick and fair peer-review system. Visit http://www.dovepress.com/testimonials.php to read real quotes from published authors. 